\title{
Type I Photoinitiator-Functionalized Block Copolymer Nanoparticles prepared by RAFT-mediated Polymerization-Induced Self-Assembly
}

\author{
Yang Du ${ }^{\mathrm{a}}$, Shuai Jia ${ }^{\mathrm{a}}$, Ying Chen ${ }^{\mathrm{b}}$, Li Zhang ${ }^{\mathrm{a}, \mathrm{b}}$, Jianbo Tan ${ }^{\mathrm{a}, \mathrm{b}}$
}

a. Department of Polymeric Materials and Engineering, School of Materials and Energy, Guangdong University of Technology, Guangzhou 510006, China.

b. Guangdong Provincial Key Laboratory of Functional Soft Condensed Matter, Guangzhou 510006,

China.

Yang Du and Shuai Jia contributed equally to this work.

*Corresponding author: tanjianbo@gdut.edu.cn 


\section{EXPERIMENTAL SECTION}

\section{Materials.}

Allyl methacrylate (AMA, Aladdin), glycidyl methacrylate (GlyMA, Aladdin), and 2-(dimethylamino) ethyl methacrylate (DMAEMA, Aladdin) were passed through a column of basic alumina (Aladdin) prior to storage under refrigeration at $4{ }^{\circ} \mathrm{C} .2$, 2-Azobisisobutyronitrile (AIBN, Aladdin) was recrystallized from ethanol prior to storage under refrigeration at $4{ }^{\circ} \mathrm{C}$. Ethyl (2,4,6-trimethylbenzoyl) phenylphosphinate (TPO-L, Tianjin Jiuri Chemical Co.LTD), poly(ethylene glycol) methyl ether methacrylate (PEGMA, $M_{\mathrm{n}}=500 \mathrm{~g} / \mathrm{mol}$, Sigma-Aldrich), ethylene glycol (EG, Aladdin), oxalyl chloride(Aladdin), poly(ethylene glycol) diacrylate (PEGDA, $M_{\mathrm{n}}=600 \mathrm{~g} / \mathrm{mol}, \quad$ Aladdin), 2-hydroxypropyl methacrylate (HPMA, Aladdin), acrylamide(AM,Aladdin), dicyclohexylcarbodiimide (DCC, Aladdin), 4-dimethylaminopyridine (DMAP, Aladdin), horseradish peroxidase (HRP, $\geq 200$ units/mg dry weight, Aladdin), 2,2'-azino-bis(3-ethylbenzothiazoline-6-sulfonic acid) (ABTS, Aladdin), hydrogen peroxide (Aladdin, 30 wt. \% stabilized aqueous solution), and $N, N$-dimethylformamide (DMF, Tianjin Damao) were used as received. L-Ascorbic acid sodium salt (NaAs, 99\%) and potassium persulfate (KPS, Aladdin) were purchased from Aladdin. KPS was recrystallized from cold water prior to use. 4-Cyano-4-(dodecylsulfanylthiocarbonyl)sulfanylpentanoic acid (CDPA) was synthesized according to a literature $\mathrm{e}^{[1]}$.

\section{Characterization.}

Transmission electron microscopy (TEM). The obtained dispersions were diluted 100-fold with water. A drop of the solution was placed on the copper grid for $3 \mathrm{~min}$ and then blotted with filter paper to remove excess solution. A drop of uranyl acetate solution $(0.5 \mathrm{wt} \%)$ was soaked on the same copper grid for $3 \mathrm{~min}$, and then blotted with filter paper to remove excess stain. For the samples of PDMAEMA-functionalized assemblies, a phosphotungstic acid solution $(2 \mathrm{wt} \%)$ in phosphate buffer $(\mathrm{pH}=7.4)$ was used for staining. Transmission electron microscope (TEM) observations were carried out on a Hitachi 7700 instrument operated at $100 \mathrm{kV}$.

Scanning electron microcopy (SEM). SEM images were collected using a Hitachi SU8010 (Tokyo, Japan) electron microscope at 5-10 kv on samples sputter-coated with gold prior imaging.

${ }^{l} H$ NMR spectroscopy. Nuclear magnetic resonance (NMR) spectra were recorded in $\mathrm{CDCl} 3, \mathrm{D}_{2} \mathrm{O}$ or DMSO using a Bruker Avance III HD $400 \mathrm{MHz}$ NMR spectrometer at a temperature of $25^{\circ} \mathrm{C}$.

Gel Permeation Chromatography (GPC). Molecular weights and polydispersities of block copolymers were measured by gel permeation chromatography (GPC) at $45{ }^{\circ} \mathrm{C}$ using a Waters 1515 GPC instrument with 
dimethylformamide (DMF) as the mobile phase and Waters styragel HR1 and HR4 columns. The eluent used was HPLC grade DMF containing $10 \mathrm{mM} \mathrm{LiBr}$ and was filtered prior to use. The flow rate of DMF was 1.0 $\mathrm{mL} / \mathrm{min}$. Linear poly(methyl methacrylate) polymers with narrow molecular weight distributions were used as standards to calibrate apparatus.

Dynamic Light Scattering $(D L S)$. Intensity-average hydrodynamic diameters of the dispersions $(0.1 \% \mathrm{v} / \mathrm{v})$ were obtained using a Brookhaven nanoparticle size-zeta potential and molecular weight analyzer. Dilute aqueous dispersions were analyzed using disposable cuvettes and all data were averaged over five consecutive runs.

Linkam TST350 equipment was used to test the mechanical properties. Compression tests were conducted at a crosshead speed of $10 \%$ strain per min. For uniaxial tensile tests, hydrogel samples were tested at a crosshead speed of $80 \mathrm{~mm} \mathrm{~min}^{-1}$.

Aqueous electrophoresis. Zeta potentials were determined as a function of solution $\mathrm{pH}$ using a Malvern Zetasizeer Nano ZS instrument equipped with an auto-titrator for adjusting $\mathrm{pH}$ value from 3 to 11 by the addition of $0.1 \mathrm{M} \mathrm{HCl}$ or $0.1 \mathrm{M} \mathrm{NaOH}$.

Ultraviolet visible photometer. UV-Visible spectra were recorded with a $1.0 \mathrm{~cm}$ quartz cuvette using a UV2450 spectrometer.

\section{Synthesis of CDPA-OH.}

A solution of CDPA $(6.51 \mathrm{~g}, 16.12 \mathrm{mmol})$ in anhydrous tetrahydrofuran $(10 \mathrm{~mL})$ was introduced in a dry flask containing anhydrous ethylene glycol $(1.00 \mathrm{~g}, 16.12 \mathrm{mmol})$. Then a solution of DCC (3.99 $\mathrm{g}, 19.34$ mmol) and DMAP (0.236 g, $1.93 \mathrm{mmol})$ in anhydrous THF $(15 \mathrm{~mL})$ was added dropwise to the reaction mixture at $0{ }^{\circ} \mathrm{C}$. The esterification reaction proceeded with stirring at room temperature for $12 \mathrm{~h}$. The product was further purified by a silica chromatography (ethyl acetate: $\mathrm{n}$-hexane $=1: 3$ ), and finally dried at $45{ }^{\circ} \mathrm{C}$ under vacuum to obtain an orange oil. Yield: $42.5 \%$.

\section{Synthesis of sodium 2,4,6-trimethylbenzoylphenylphosphinate (TPO-Na).}

A mixture of TPO-L (10.00 g, $31.60 \mathrm{mmoL})$, anhydrous NaI (5.25 g, $35.03 \mathrm{mmoL})$ and 2-butanone (50 $\mathrm{mL}$ ) was stirred at $40{ }^{\circ} \mathrm{C}$ for $30 \mathrm{~min}$. The resulting solution was heated at $65^{\circ} \mathrm{C}$ for $24 \mathrm{~h}$. The suspension was cooled to room temperature and filtered, washed with cold 2-butanone $(2 \times 20 \mathrm{~mL})$ and dried under vacuum. Yield: $82.6 \%$.

\section{Synthesis of 2,4,6-trimethylbenzoylphenylphosphinic acid (TPO-OH).}

A solution of TPO-Na $(7.20 \mathrm{~g}, 23.22 \mathrm{mmoL})$ in distilled water $(50 \mathrm{~mL})$ was stirred at the room 
temperature. Then aqueous solution of $\mathrm{H}_{2} \mathrm{SO}_{4}(0.5 \mathrm{M}, 20 \mathrm{~mL})$ was added to reach the $\mathrm{pH}$ of 1 , and the product was precipitated gradually. Ethyl acetate $(200 \mathrm{~mL})$ was added to the solution, and the organic phase was separated. The aqueous layer was extracted with ethyl acetate $(2 \times 100 \mathrm{~mL})$. The total organic layers were washed with water $(2 \times 100 \mathrm{~mL})$ and dried over anhydrous $\mathrm{Na}_{2} \mathrm{SO}_{4}$. After evaporation of the solvent under reduced pressure, TPO-OH was obtained as a pale yellow solid. Yield: $67.4 \%$.

\section{Synthesis of 2,4,6-trimethylbenzoylphenylphosphinic acid chloride (TPO-Cl).}

Oxalyl chloride $(1.24 \mathrm{~mL}, 10.40 \mathrm{mmol})$ was added into a solution containing TPO-OH $(1.50 \mathrm{~g}, 5.20$ $\mathrm{mmol})$ and anhydrous dichloromethane $(15 \mathrm{~mL})$ at $0{ }^{\circ} \mathrm{C}$. The mixture was stirred at room temperature for $24 \mathrm{~h}$. After evaporation of the solvent under reduced pressure, a pale yellow oil was obtained and used in next step without further purification.

\section{Synthesis of TPO-CDPA.}

A solution of TPO-Cl $(1.596 \mathrm{~g}, 5.20 \mathrm{mmol})$ in anhydrous dichloromethane $(10 \mathrm{~mL})$ was added into a solution containing CDPA-OH $(2.33 \mathrm{~g}, 5.20 \mathrm{mmol})$ and anhydrous dichloromethane $(20 \mathrm{~mL})$ at the room temperature. The resulting mixture was stirred at room temperature for $5 \mathrm{~h}$. The product was further purified by a silica chromatography (ethyl acetate: dichloromethane $=1: 4$ ), and finally dried at $45^{\circ} \mathrm{C}$ under vacuum to obtain an orange oil. Yield: 59.4\%.

\section{Synthesis of TPO-PPEGMA -CDPA macro-RAFT agents.}

For the synthesis of TPO-PPEGMA ${ }_{15.4}$-CDPA: PEGMA $(25.00 \mathrm{~g}, 50.0 \mathrm{mmol})$, TPO-CDPA $(2.11 \mathrm{~g}, 2.94$ mmol), AIBN (0.10 g, $0.61 \mathrm{mmol}), 1,3,5$-trioxacyclohexane $(0.45 \mathrm{~g}, 5.0 \mathrm{mmol})$, and 1,4-dioxane $(25.00 \mathrm{~g})$ were weighed into a $100 \mathrm{~mL}$ round bottom flask and purged with nitrogen for $45 \mathrm{~min}$. The flask was then immersed into a preheated oil bath at $70{ }^{\circ} \mathrm{C}$ for $3 \mathrm{~h}$ (Monomer conversion $=90.4 \%$ as judged by ${ }^{1} \mathrm{H} \mathrm{NMR}$ ). The polymerization was then quenched by immersion in ice water and exposure to air. The product was precipitated by adding excess of hexane and washed several times with additional hexane. The precipitated product was then dried at $45{ }^{\circ} \mathrm{C}$ under vacuum overnight. The obtained macro-RAFT agent was denoted as TPO-PPEGMA 15.4 -CDPA. DMF GPC trace gave $M_{\mathrm{n}}=10.9 \mathrm{~kg} / \mathrm{mol}$ and $M_{\mathrm{w}} / M_{\mathrm{n}}=1.17$. Other macro-RAFT agents were synthesized following the same protocol.

\section{$\mathrm{H}_{2} \mathrm{O}_{2}$ protocol for the cleavage of RAFT end-groups.}

TPO-PPEGMA ${ }_{26}$-CDPA $(0.80 \mathrm{~g})$ was dissolved with $15.15 \mathrm{~g} \mathrm{H}_{2} \mathrm{O}$ in a $50 \mathrm{~mL}$ round bottom flask. A certain amount of $\mathrm{H}_{2} \mathrm{O}_{2}$ solution $\left(30 \% \mathrm{w} / \mathrm{w}, 0.0667 \mathrm{~g},\left[\mathrm{H}_{2} \mathrm{O}_{2}\right] /[\mathrm{CDPA}]=10.0\right)$ was added to this solution. The resulting reaction solution was immersed in an oil bath at $70{ }^{\circ} \mathrm{C}$ for $9 \mathrm{~h}$ and left exposed to air. The solution 
was freeze dried for further use.

\section{Preparation of TPO-functionalized block copolymer nanoparticles by photo-PISA.}

In a typical experiment for the synthesis of TPO-PPEGMA ${ }_{15.4}-\mathrm{PHPMA}_{350}-\mathrm{CDPA}(20 \% \mathrm{w} / \mathrm{w}$ HPMA): TPO-PPEGMA 15.4 -CDPA $\left(0.167 \mathrm{~g}, 1.99 \times 10^{-2} \mathrm{mmol}\right)$, HPMA $(1.00 \mathrm{~g}, 6.94 \mathrm{mmol})$, and water $(4.00 \mathrm{~g})$ were weighed into a $10 \mathrm{~mL}$ round bottom flask. The reaction was purged with nitrogen for $20 \mathrm{~min}$, and then exposed to a LED lamp $\left(\lambda=530 \mathrm{~nm}, 10.0 \mathrm{~mW} / \mathrm{cm}^{2}\right)$ for $24 \mathrm{~h}$. The polymerization was quenched by exposure to air.

\section{Preparation of TPO-functionalized block copolymer nanoparticles by redox initiated PISA.}

In a typical experiment for the synthesis of TPO-PPEGMA ${ }_{15.4}-\mathrm{PHPMA}_{300}-\mathrm{CDPA}(20 \% \mathrm{w} / \mathrm{w}$ HPMA): TPO-PPEGMA ${ }_{15.4}$-CDPA $(0.19 \mathrm{~g}, 0.023 \mathrm{mmol})$, HPMA $(1.0 \mathrm{~g}, 6.94 \mathrm{mmol})$, and water $(3.754 \mathrm{~g})$ were weighed into a $10 \mathrm{~mL}$ round bottom flask. The reaction mixture was degassed with nitrogen for $20 \mathrm{~min}$, and then degassed solutions of KPS $(208 \mu \mathrm{L}, 10 \mathrm{mg} / \mathrm{mL} 7.708 \mu \mathrm{mol})$ and NaAs $(38 \mu \mathrm{L}, 40 \mathrm{mg} / \mathrm{mL} 7.707 \mu \mathrm{mol})$ ( $\left.[\mathrm{NaAs}]:[\mathrm{KPS}]:\left[\mathrm{PPEGMA}_{15.4} \mathrm{CDPA}-\mathrm{TPO}\right]=1: 1: 3\right)$ were injected in that order via microsyringes. Polymerizations were proceeded at room temperature for $2 \mathrm{~h}$ and full monomer conversion was achieved in each case.

\section{Kinetic Study of RAFT-mediated dispersion polymerization under green light irradiation.}

HPMA (2.40 g, $16.65 \mathrm{mmol})$, TPO-PPEGMA $15.4-\mathrm{CDPA}(0.6994 \mathrm{~g}, 0.083 \mathrm{mmol})$ and water $(13.60 \mathrm{~g})$ were weighed into a $25 \mathrm{~mL}$ round bottom flask. The reaction mixture was purged with nitrogen for $20 \mathrm{~min}$, and then irradiated by a visible light LED lamp $\left(\lambda=530 \mathrm{~nm}, 10.0 \mathrm{mw} / \mathrm{cm}^{2}\right)$. Samples were withdrawn at predetermined time intervals by syringes under nitrogen, and polymerizations were quenched by exposure to air and the addition of a small amount of hydroquinone. The samples were then analyzed by ${ }^{1} \mathrm{H}$ NMR spectroscopy and GPC.

Preparation of PGlyMA-functionalized vesicles using TPO-PPEGMA ${ }_{15.4}$-PHPMA $_{350}$-CDPA vesicles as seeds

In a typical experiment ([GlyMA]/[TPO-PPEGMA ${ }_{15.4}$ PHPMA $\left._{350}-\mathrm{CDPA}\right]=100 / 1$ ): A solution of GlyMA (90.4 mg, $0.64 \mathrm{mmol})$ in water $(2.95 \mathrm{~g})$ was added into the dispersion of TPO-PPEGMA ${ }_{15.4}-$ PHPMA $_{350}$-CDPA vesicles (1.66 g, containing $0.38 \mathrm{~g}$ solids, $\left.6.36 \mu \mathrm{mol}\right)$. The reaction mixture was purged with nitrogen for $20 \mathrm{~min}$, and then irradiated by a visible light LED lamp $(\lambda=405 \mathrm{~nm}$, $0.5 \mathrm{~mW} / \mathrm{cm}^{2}$ ) at room temperature for $1 \mathrm{~h}$. The reaction was quenched by exposure to air. 


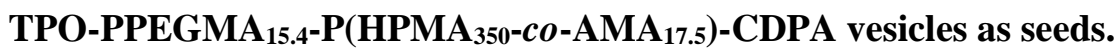

In a typical experiment ([DMAEMA]/[TPO-PPEGMA $\left.\left.{ }_{15.4}-\mathrm{P}\left(\mathrm{HPMA}_{350}-\mathrm{co}-\mathrm{AMA}_{17.5}\right)-\mathrm{CDPA}\right]=100 / 1\right):$ An aqueous solution of DMAEMA (48.7 $\mathrm{mg}, 0.31 \mathrm{mmol})$ in water $(1.51 \mathrm{~g})$ were added dropwise to the dispersion of TPO-PPEGMA ${ }_{15.4}-\mathrm{P}\left(\mathrm{HPMA}_{350}\right.$-co-AMA $\left.{ }_{17.5}\right)$-CDPA vesicles $(0.81 \mathrm{~g}$, containing $0.19 \mathrm{~g}$ solids, $3.08 \mu \mathrm{mol})$. The reaction mixture was then purged with nitrogen for $20 \mathrm{~min}$, sealed, and then irradiated by a visible light LED lamp $\left(\lambda=405 \mathrm{~nm}, 0.5 \mathrm{~mW} / \mathrm{cm}^{2}\right)$ at room temperature for $1 \mathrm{~h}$. The obtained sample was purified by three centrifugation-redispersion cycles in water.

\section{Preparation of Hydrogels using TPO-PPEGMA26-P(HPMA $\left.{ }_{300}-c o-A M A_{15}\right)$-CDPA spheres.}

In a typical experiment for the preparation of hydrogels: AM (1.00 g), PEGDA (3.6 mg), TPO-PPEGMA 26 -P(HPMA $\left.300-c o-\mathrm{AMA}_{15}\right)$ spheres (4-10\% w/w with respect to AM), and water $(4.00 \mathrm{~g})$ were added in glass bottles. After bubbling with nitrogen for $20 \mathrm{~min}$, the reaction mixture was injected into a PTFE mold and covered with glass plate, and then exposed to a LED lamp $\left(2.0 \mathrm{~mW} / \mathrm{cm}^{2}, 405 \mathrm{~nm}\right)$ for $1 \mathrm{~h}$. Other hydrogels were prepared following the same protocol.

Preparation of HRP-loaded TPO-PPEGMA ${ }_{15.4}-\mathrm{P}\left(\mathrm{HPMA}_{300}-\right.$-co-AMA $\left._{15}\right)$-CDPA vesicles by redox initiated RAFT-mediated dispersion polymerization.

TPO-PPEGMA ${ }_{15.4-C D P A}(0.19 \mathrm{~g}, 0.023$ mmol), HPMA (1.0 g, 6.94 mmol), AMA (0.0438 g, 0.347 $\mathrm{mmol})$, HRP $(3.2 \mathrm{mg})$, and water $(3.754 \mathrm{~g})$ were weighed into a $10 \mathrm{~mL}$ round bottom flask. The reaction mixture was degassed with nitrogen for $20 \mathrm{~min}$, and then degassed solutions of KPS $(208 \mu \mathrm{L}, 10 \mathrm{mg} / \mathrm{mL}$, $7.708 \mu \mathrm{mol})$ and NaAs $(38 \mu \mathrm{L}, 40 \mathrm{mg} / \mathrm{mL}, 7.707 \mu \mathrm{mol})([\mathrm{NaAs}]:$ [KPS]: [TPO-PPEGMA $15.4-\mathrm{CDPA}]=1: 1: 3)$ were injected in that order via microsyringes. The polymerization was proceeded for $2 \mathrm{~h}$ at room temperature to ensure full monomer conversion. The obtained sample was diluted with deionized water and purified by three centrifugation-redispersion cycles to remove free HRP. Finally, HRP-loaded vesicles were diluted to 5\%

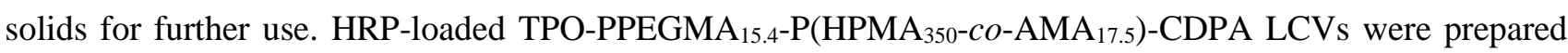
using the same protocol.

\section{Enzymatic activity of Hydrogels prepared with HRP-loaded vesicles or HRP-loaded LCVs.}

In a typical protocol, a small piece of hydrogel prepared with a certain concentration of HRP-loaded vesicles or HRP-loaded LCVs, ABTS solution $(1 \mathrm{mM}, 2000 \mu \mathrm{L})$ were added to a quartz cuvette and then incubated at a certain temperature for 3 min. Finally, a $\mathrm{H}_{2} \mathrm{O}_{2}$ solution $(0.30 \mathrm{wt} \%, 100 \mu \mathrm{L})$ at the same temperature was added to the cuvette. The change in absorbance at $405 \mathrm{~nm}$ was recorded every second using a UV-vis spectrophotometer. 


\section{ADDITIONAL RESULTS}

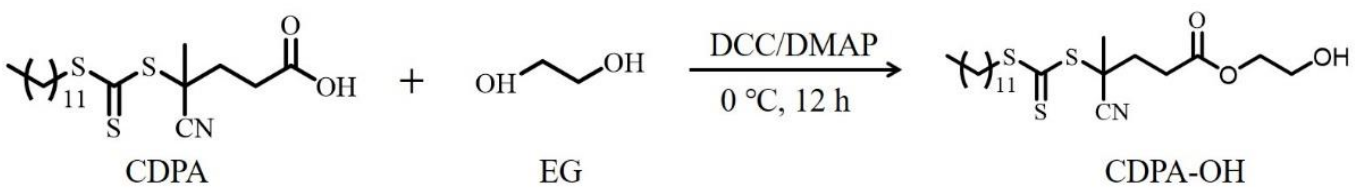

Scheme S1. Schematic illustration for the synthesis of CDPA-OH.<smiles>CCOP(=O)(c1ccccc1)c1c(C)cc(C)cc1C</smiles>

TPO-L

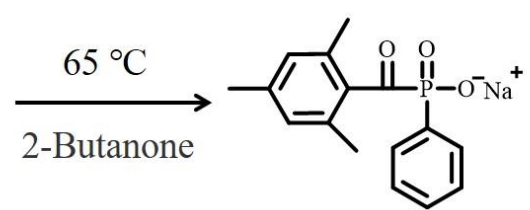

$\mathrm{TPO}-\mathrm{Na}^{+}$

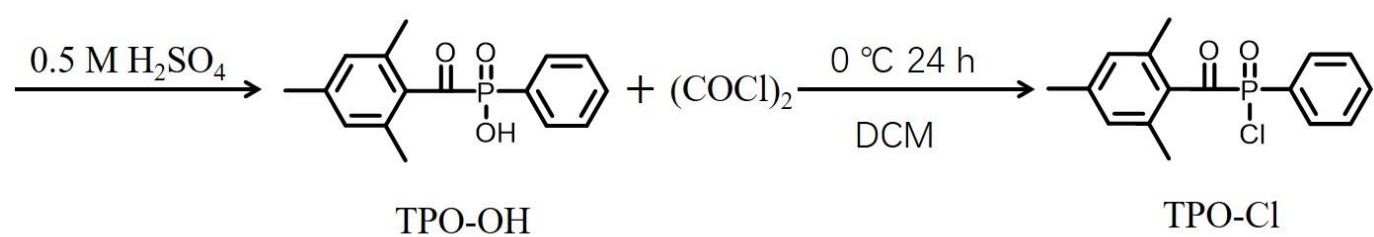

Scheme S2. Schematic illustration for the synthesis of TPO-Cl.

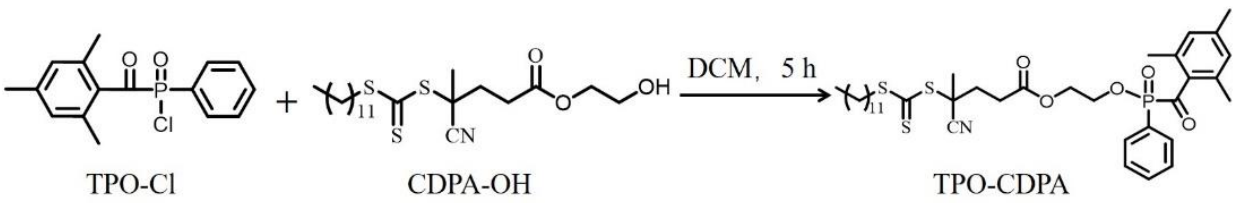

Scheme S3. Schematic illustration for the synthesis of CDPA-TPO.

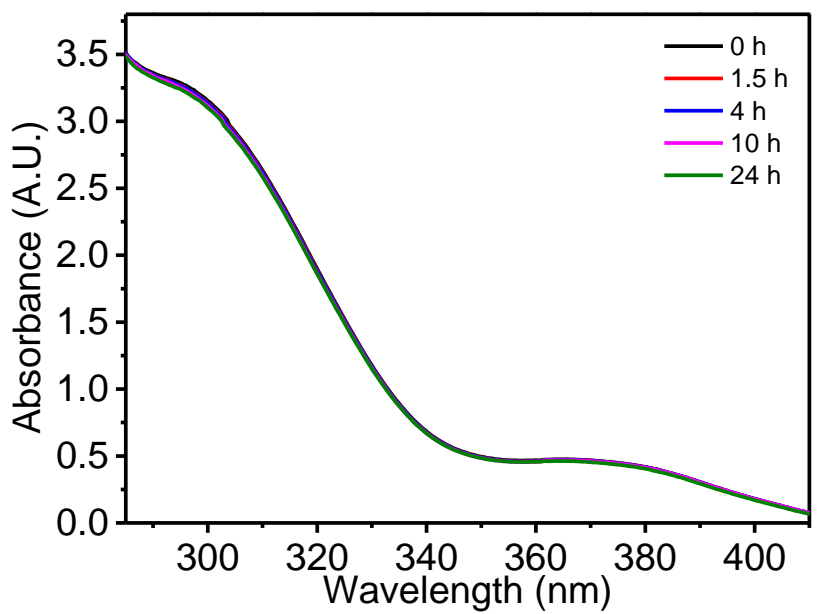

Figure S1. UV-vis absorbance spectra of TPO-PPEGMA ${ }_{26}$ in water under green light irradiation $(\lambda=530 \mathrm{~nm}$, 
$\left.10 \mathrm{~mW} / \mathrm{cm}^{2}\right)$ at different times.

Table S1. Summary of synthesis parameters, monomer conversions, GPC data, DLS, and TEM characterization for a series of TPO-PPEGMA ${ }_{15.4}-$ PHPMA $_{n}$-CDPA diblock copolymers prepared via aqueous photo-PISA of HPMA mediated by TPO-PPEGMA ${ }_{15.4}$-CDPA under green light irradiation $(\lambda=530 \mathrm{~nm}, 10$ $\left.\mathrm{mW} / \mathrm{cm}^{2}\right)$.

\begin{tabular}{|c|c|c|c|c|c|c|c|c|c|}
\hline Exp. & Target & Monomer & Monomer & Actual & $M_{\mathrm{n}}^{\mathrm{a}}$ & $M_{\mathrm{w}} / M_{\mathrm{n}}^{\mathrm{a}}$ & $D_{\mathrm{h}}$ & PDI & TEM \\
\hline & DP & concentration & conversion & DP & $\left(\mathrm{kg} \cdot \mathrm{mol}^{-1}\right)^{\mathrm{a}}$ & & (nm) & & morphology ${ }^{\mathrm{b}}$ \\
\hline 1 & 200 & $10 \% \mathrm{w} / \mathrm{w}$ & $100 \%$ & 200 & 63.1 & 1.35 & 36.8 & 0.068 & S \\
\hline 2 & 300 & $10 \% \mathrm{w} / \mathrm{w}$ & $98.6 \%$ & 296 & 100.0 & 1.36 & 275.9 & 0.253 & W \\
\hline 3 & 200 & $15 \% \mathrm{w} / \mathrm{w}$ & $100 \%$ & 200 & 67.5 & 1.30 & 39.3 & 0.108 & $\mathrm{~S}+\mathrm{W}$ \\
\hline 4 & 300 & $15 \% \mathrm{w} / \mathrm{w}$ & $100 \%$ & 300 & 104.3 & 1.39 & 356.4 & 0.202 & $\mathrm{~W}+\mathrm{V}$ \\
\hline 5 & 400 & $15 \% \mathrm{w} / \mathrm{w}$ & $93.8 \%$ & 375 & 125.3 & 1.50 & 524.0 & 0.150 & V \\
\hline 6 & 200 & $20 \% \mathrm{w} / \mathrm{w}$ & $100 \%$ & 200 & 66.8 & 1.24 & 49.0 & 0.136 & $\mathrm{~S}+\mathrm{W}$ \\
\hline 7 & 300 & $20 \% \mathrm{w} / \mathrm{w}$ & $100 \%$ & 300 & 94.7 & 1.45 & 296.0 & 0.233 & $\mathrm{~W}+\mathrm{V}$ \\
\hline 8 & 350 & $20 \% \mathrm{w} / \mathrm{w}$ & $100 \%$ & 350 & 114.7 & 1.41 & 398.2 & 0.178 & V \\
\hline 9 & 400 & $20 \% \mathrm{w} / \mathrm{w}$ & $100 \%$ & 400 & 97.9 & 1.41 & 1289.5 & 0.336 & $\mathrm{LCVs}$ \\
\hline
\end{tabular}

a GPC data was obtained against poly(methyl methacrylate) standards; b TEM morphology consists of spheres $(\mathrm{S})$, worms $(\mathrm{W})$, vesicles $(\mathrm{V})$, and large compound vesicles (LCVs). 


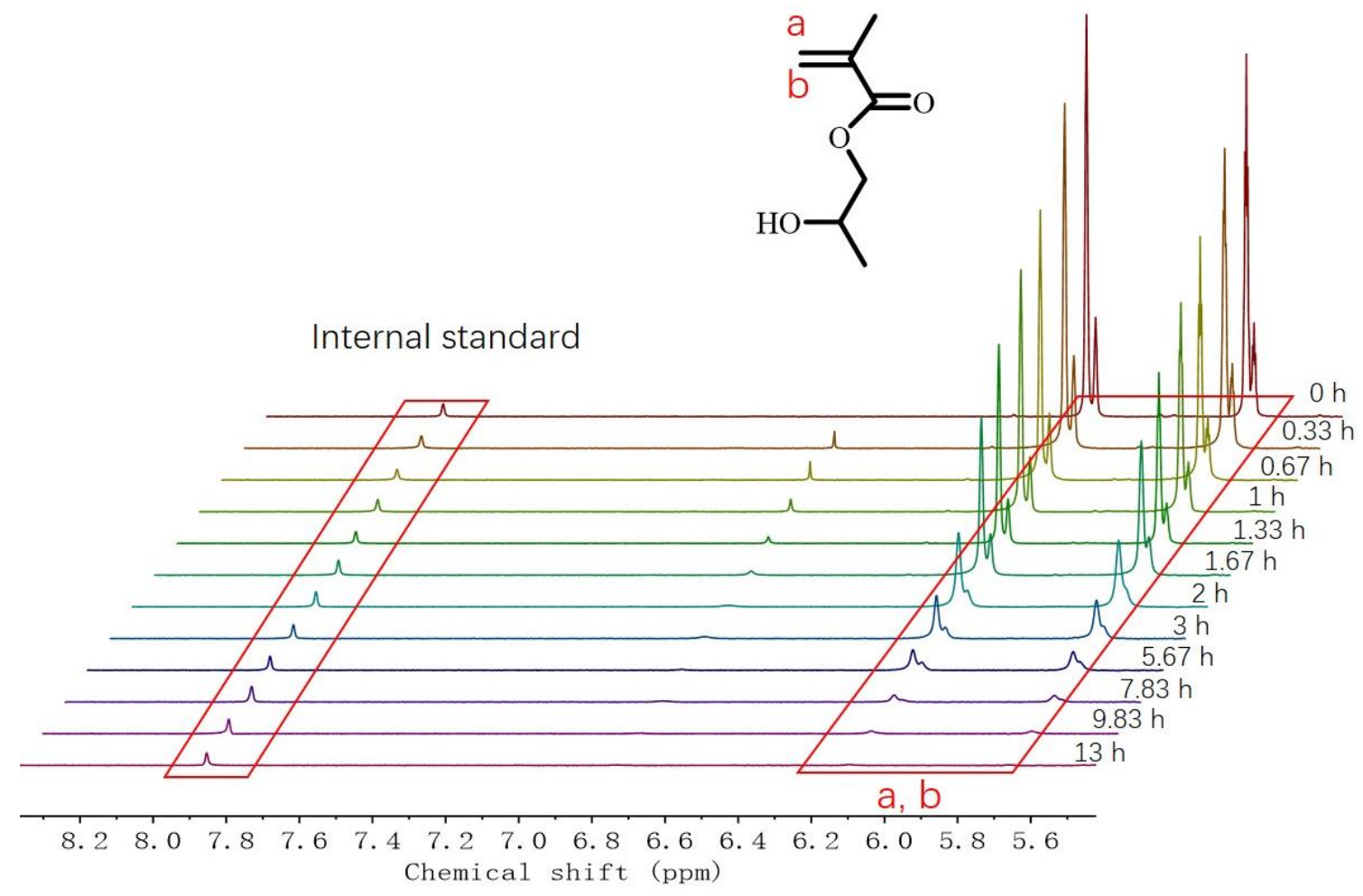

Figure S2. ${ }^{1} \mathrm{H}$ NMR spectra of reaction mixtures withdrawn during aqueous photo-PISA of HPMA (15\% w/w, target DP of 200) mediated by TPO-PPEGMA ${ }_{15.4}$-CDPA under green light irradiation $(\lambda=530 \mathrm{~nm}, 10$ $\left.\mathrm{mW} / \mathrm{cm}^{2}\right)$.
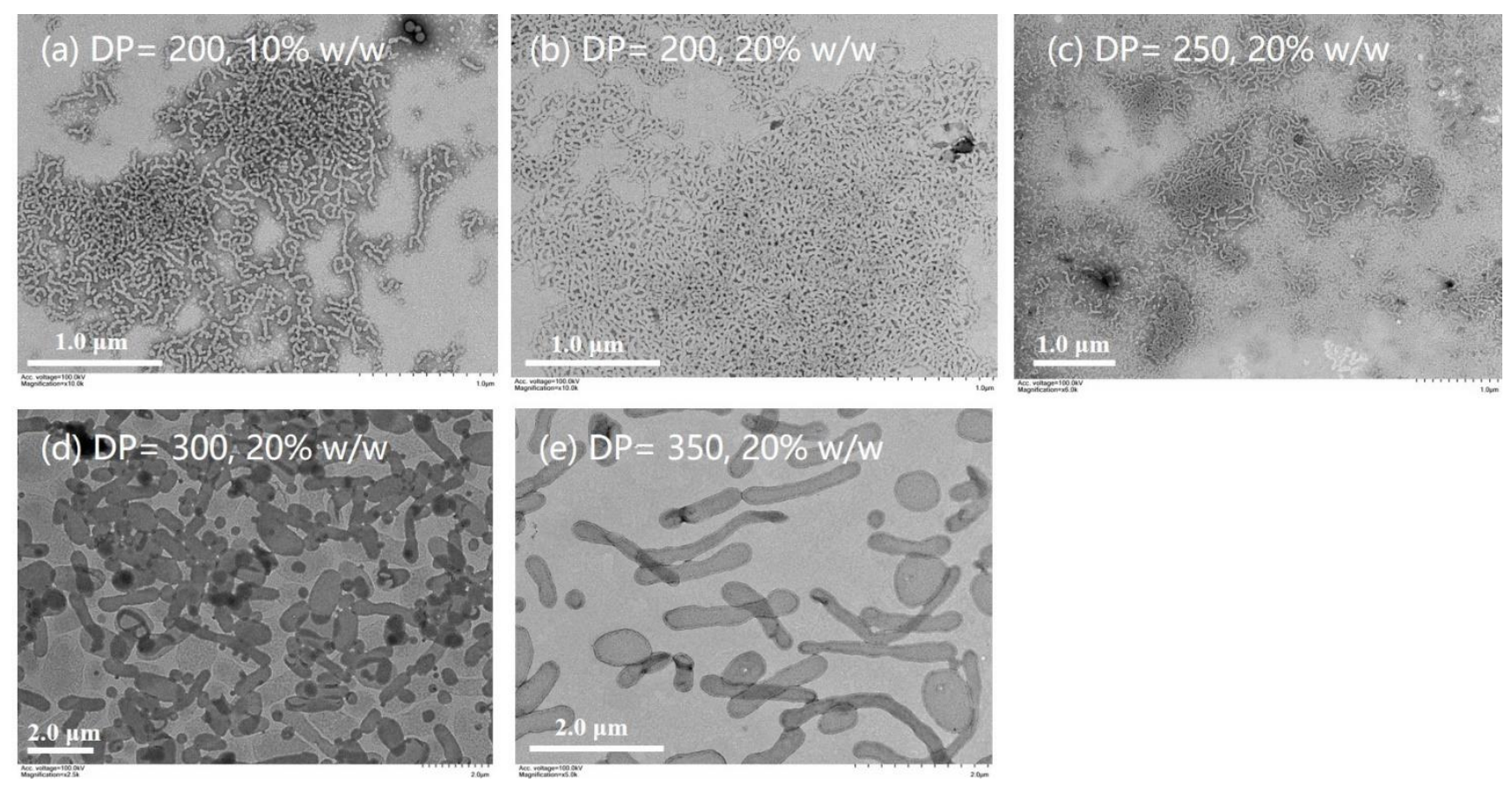

Figure S3. TEM images of TPO-PPEGMA $15.4-$ PHPMA $_{\mathrm{n}}$-CDPA diblock copolymer nanoparticles prepared via aqueous redox initiated PISA of HPMA by varying the HPMA concentration and the DP of PHPMA. 

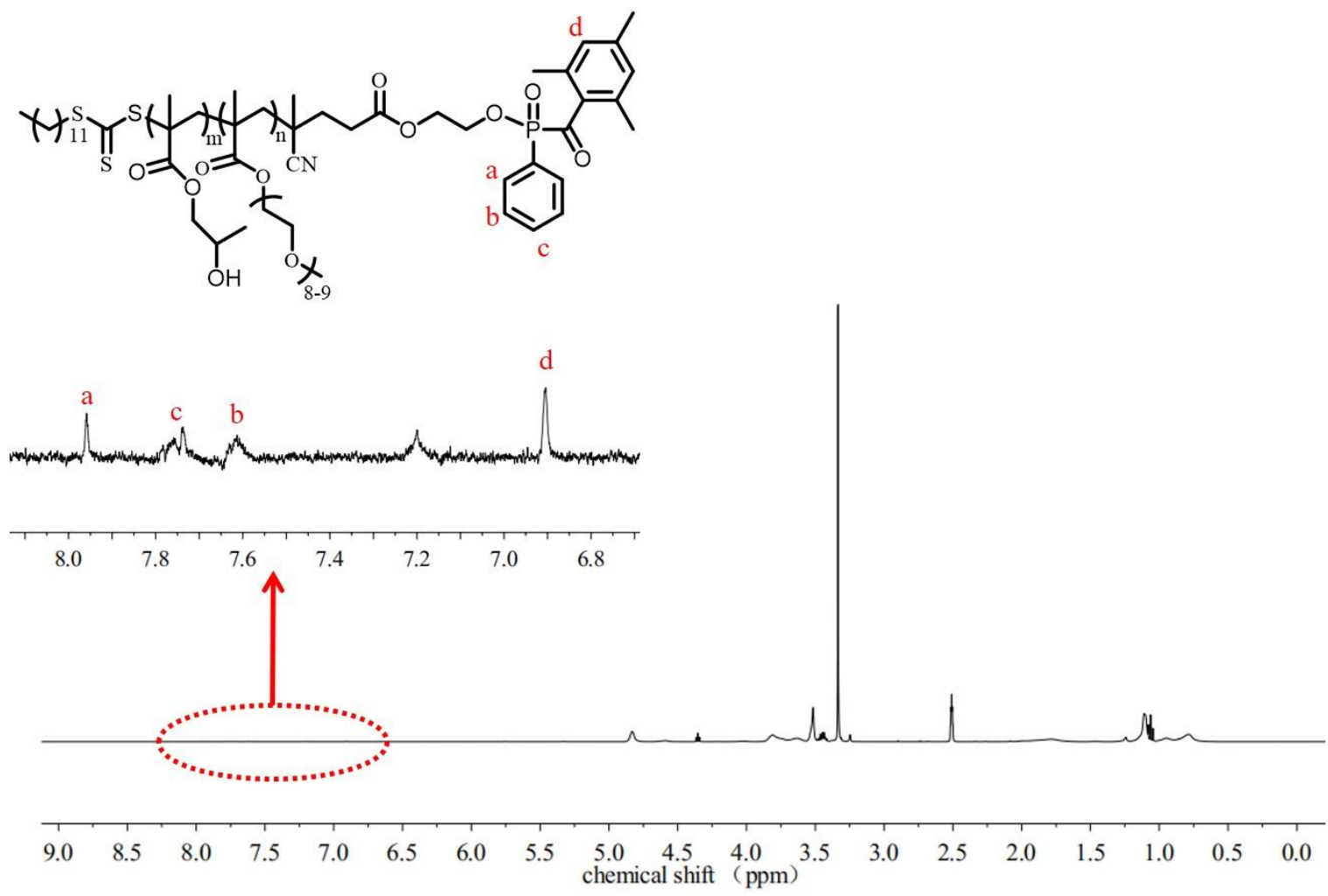

Figure S4. ${ }^{1} \mathrm{H}$ NMR spectrum of TPO-PPEGMA ${ }_{15.4}-\mathrm{PHPMA}_{250}$-CDPA prepared by aqueous photo-PISA.
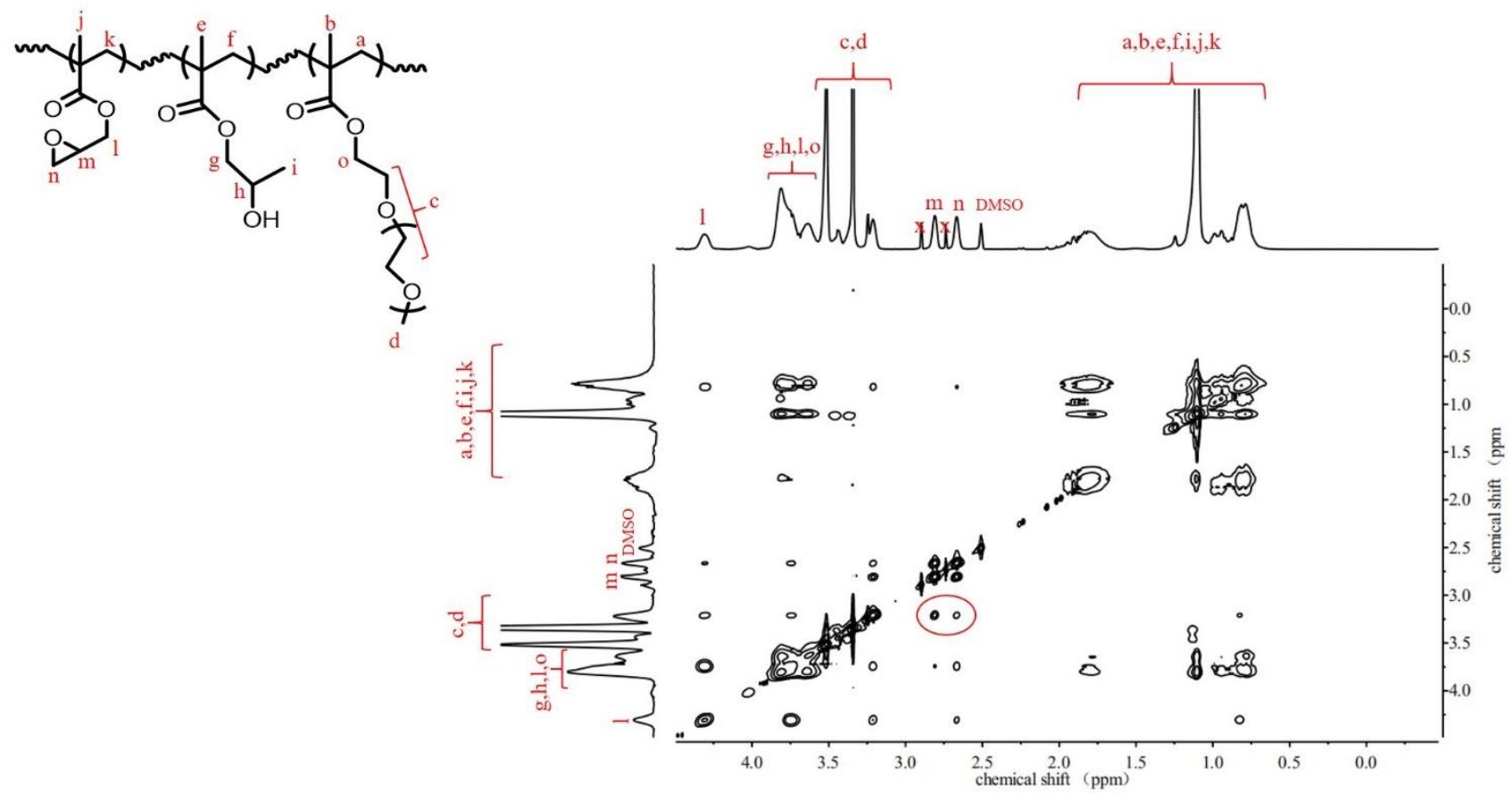

Figure S5. 2D- ${ }^{1} \mathrm{H}-\mathrm{NOESY}$ NMR spectra in DMSO- $d_{6}$ of PGlyMA-functionalized vesicles prepared with the [GlyMA]/[TPO-PPEGMA ${ }_{15.4}$ PHPMA $_{350}$-CDPA] ratio of 100 . The red circle showed cross signals between peak $(m, n)$ and peak $(c, d)$, indicating the formation of PGlyMA on the TPO side. 


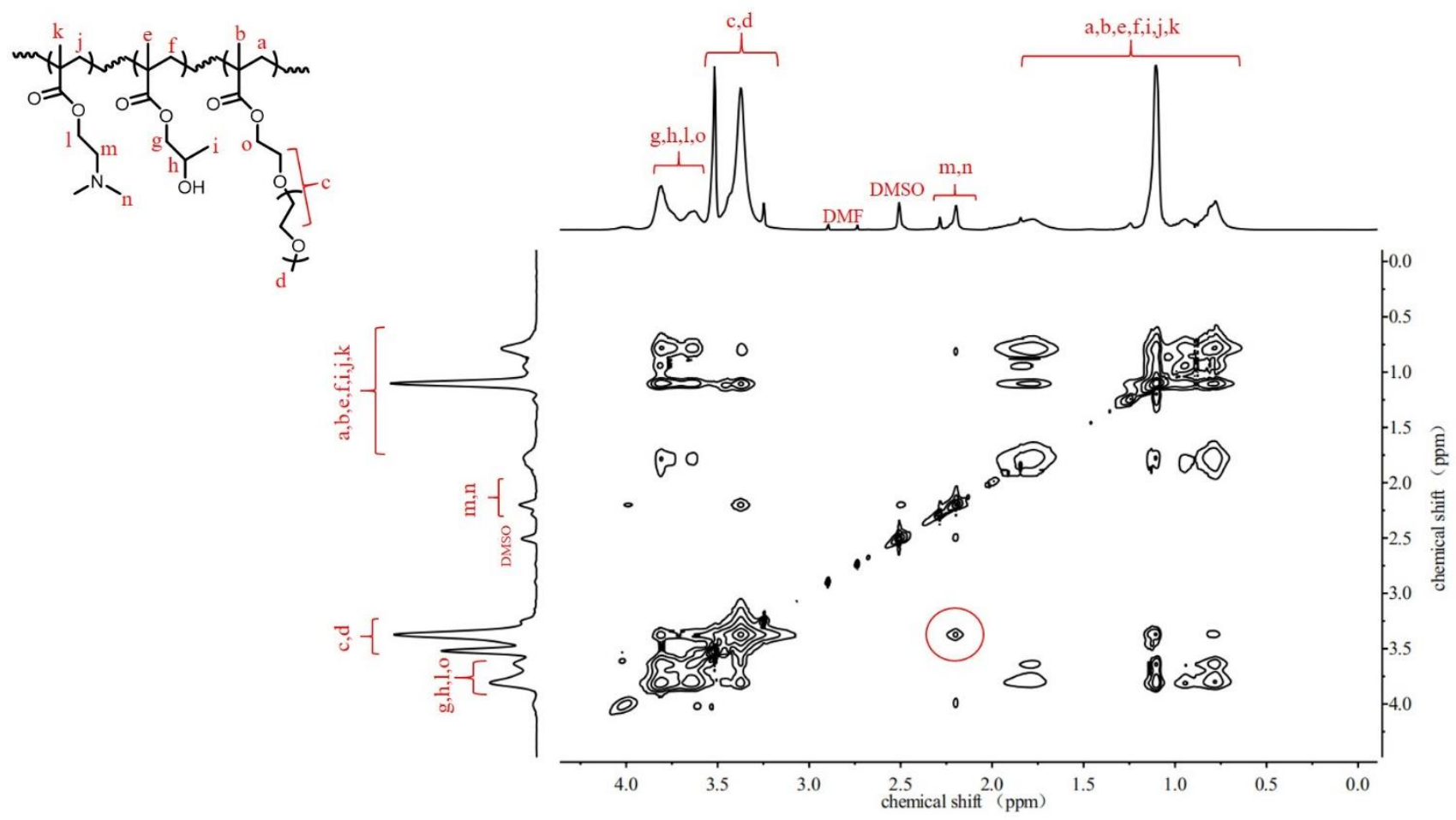

Figure S6. 2D- ${ }^{1} \mathrm{H}-\mathrm{NOESY}$ NMR spectra in DMSO- $d_{6}$ of PDMAEMA-functionalized vesicles prepared with the [DMAEMA]/[TPO-PPEGMA ${ }_{15.4}$ PHPMA $_{350}$-CDPA] ratio of 100. The red circle showed cross signals between peak $(m, n)$ and peak $(c, d)$, indicating the formation of PDMAEMA on the TPO side.

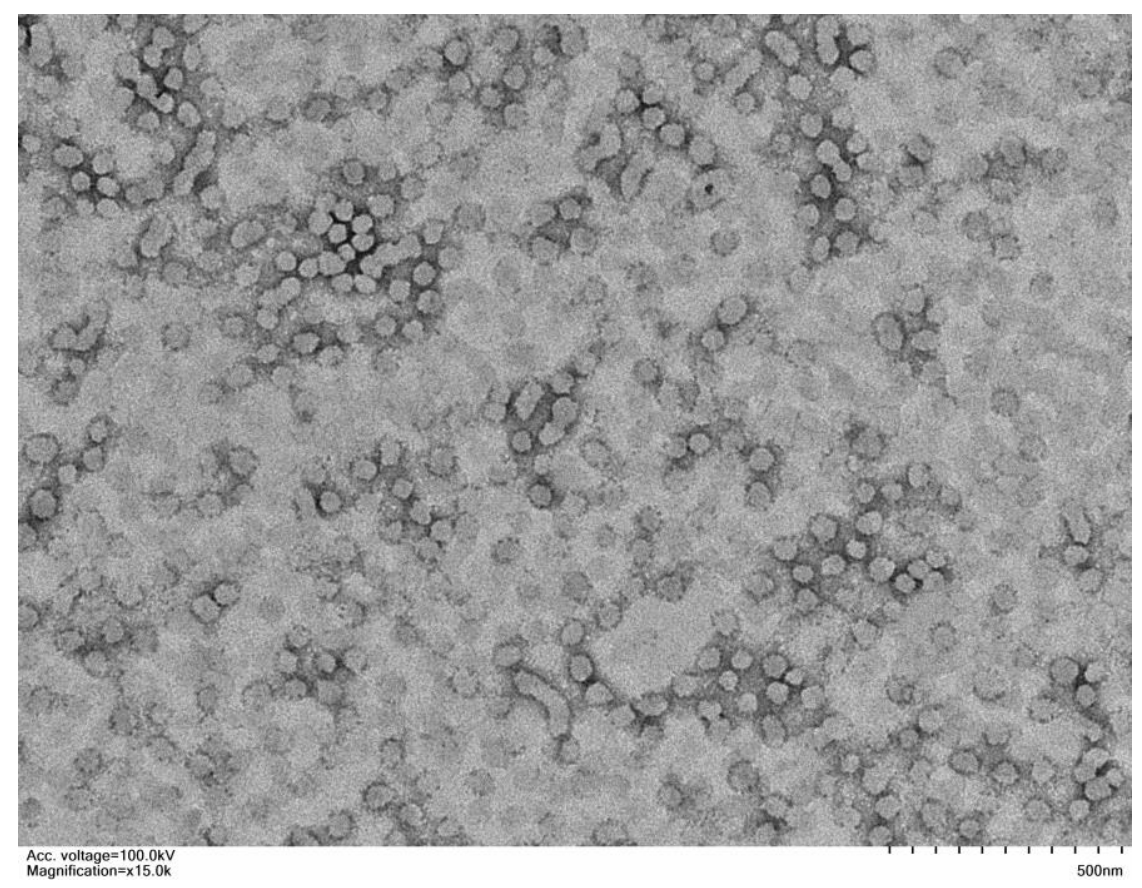

Figure S7. TEM image of TPO-PPEGMA $26-\mathrm{P}\left(\mathrm{HPMA}_{300^{-}}-\mathrm{O}-\mathrm{AMA}_{15}\right)-\mathrm{CDPA}$ spheres prepared by photo-PISA of $\operatorname{HPMA}(20 \% \mathrm{w} / \mathrm{w})$. 

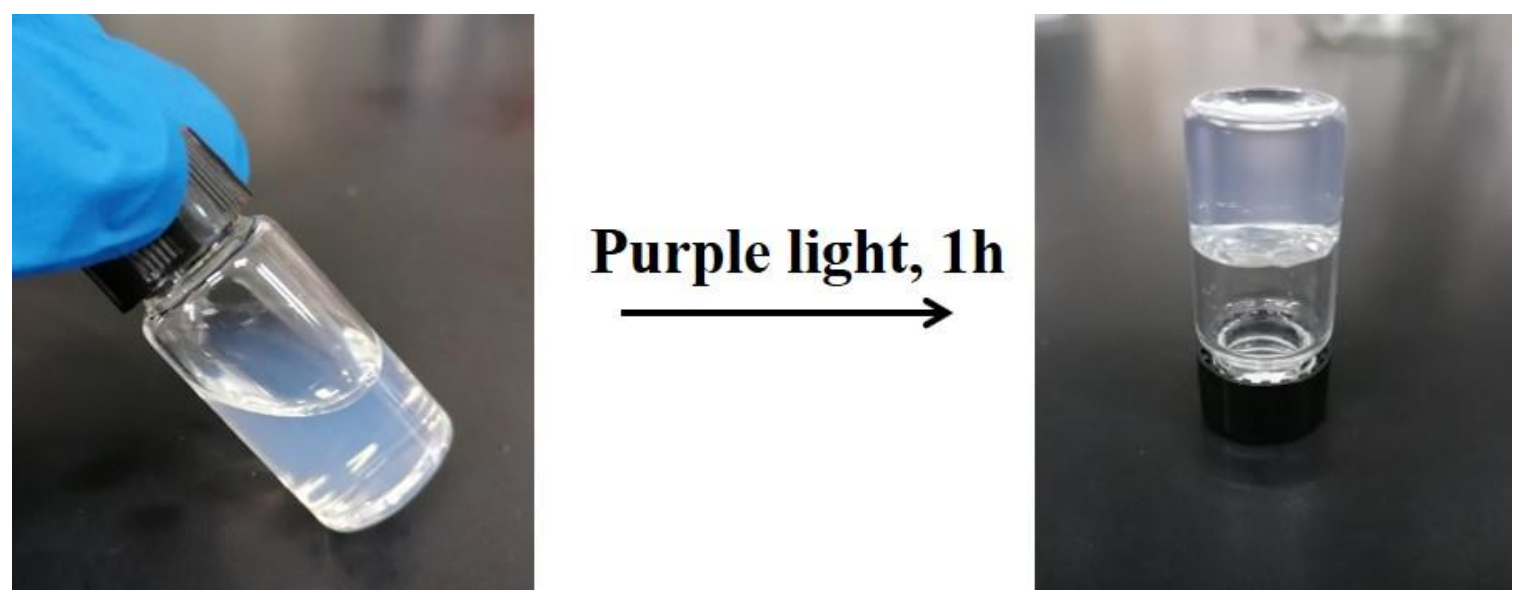

Figure S8. Images demonstrate the formation of hydrogels using TPO-functionalized block copolymer nanoparticles after purple light irradiation in the presence of AM and PEGDA.

\section{REFERENCE}

[1] Shen, W, et al. Biocompatible, Antifouling, and Thermosensitive Core-Shell Nanogels Synthesized by RAFT Aqueous Dispersion Polymerization. Macromolecules, 2011, 44(8): p. 2524-2530. 